\title{
Screening for and purification of novel self-aggregatable lectins reveal a new functional lectin group in the bark of leguminous trees
}

\section{Makiko Yamamoto, Chieko Ina, Kotone Sano, Hiroko Matsushita-Oikawa, Haruko Ueda*, Yayoi Takehara, Hiroko Takekawa, and Haruko Ogawa ${ }^{1}$}

Department of Advanced Biosciences, Graduate School of Humanities and Sciences, Ochanomizu University, Bunkyo-ku, Tokyo 112-8610, Japan

*Present address: Department of Botany, Graduate School of Science, Kyoto University, Sakyo-ku, Kyoto 606-8502

\begin{abstract}
A solubility-insolubility transition assay was used to screen the bark and stems of seven leguminous trees and
\end{abstract}

plants for self-aggregatable lectins. Novel lectins were found in two trees, Robinia pseudoacacia and Wisteria

floribunda, but not in the leguminous plants. The Robinia lectin was isolated from coexisting lectin by combined

affinity chromatographies on various sugar adsorbents. The purified lectins proved to be differently glycosylated

glycoproteins. One lectin exhibited the remarkable characteristics of self-aggregatable lectins: localization in the

bark of legume trees, self-aggregation dissociated by $N$-acetylglucosamine/mannose, and coexistence with

$\mathrm{N}$-acetylgalactosamine/galactose-specific lectins, which are potential endogenous receptors. Self-aggregatable

1 *To whom correspondence should be addressed: Department of Advanced Biosciences, Graduate School of Humanities and Sciences, Ochanomizu University, 2-1-1 Otsuka, Bunkyo-ku, Tokyo 112-8610, Japan. Tel/Fax: +81-3-5978-5343 E-mail: hogawa@cc.ocha.ac.jp. Abbreviations. Sophoragrin and Robiniagrin, self-aggregatable lectins in bark of Sophora japonica and Robinia pseudoacacia; B-SJA-I and B-RPL-I, Gal/GalNAc-specific lectins in bark of Sophora japonica and Robinia pseudoacacia; CLA, lectins in bark of Cladrastis lutea. 
lectins are a functional lectin group that can link enhanced photosynthesis to dissociation of glycoproteins.

Key Words: lectin, self-aggregation, endogenous receptor, legume bark, Robinia pseudoacacia, Wisteria

floribunda

\section{Introduction}

A number of lectins have been found to date in extracts of various plant tissues, especially the seeds, leaves,

stems, and roots [1-3]. Although lectins are specific adhesive reagents for glycoconjugates [4, 5], the biological

function of vegetative lectins, except for those in roots, remains unclear because their endogenous receptors have

not been elucidated and lectin-deficient mutants of legume plants are not yet available. Among the lectins in

vegetative organs, the sugar-dependent self-aggregatable lectin is the only one that was found to interact with

endogenous ligands including itself, but it had been found in only two species, making it impossible to presume its

function.

Sophoragrin, a Man/Glc/GlcNAc-specific lectin in the bark of Sophora japonica (Japanese pagoda tree) discovered in 1990, is the first lectin known to exhibit self-aggregation; that is, it precipitates after the removal of specific sugars and becomes soluble in their presence. It was discovered as B-SJA-II (bark S. japonica agglutinin II) [6], while B-SJA-I is a galactose-specific non-self-aggregatable lectin in S. japonica bark. Sophoragrin consists of four approximately 13-19 $\mathrm{kDa}$ glycopeptides that are generated by division of two kinds of precursor peptides, whereas B-SJA-I and most hitherto-reported legume lectins have a subunit size of around 30 $\mathrm{kDa}[1,6]$. Each sophoragrin glycopeptide contains one or three potential N-glycosylation sites [7]. B-SJA-I and Sophoragrin are the two major glycoproteins in the bark [8] that colocalize 
in the parenchymal vacuole with seasonal increases in the autumn and decreases in the spring [9, 10]. During the subsequent decade, CLA-I and CLA-II were found in the bark of the leguminous tree Cladristis lutea (yellowwood) [11]. Both CLA-I and CLA-II are Man/Glc-specific major glycoproteins in the bark, and CLA-I consists of four 15-17 kDa subunits while CLA-II has four $30 \mathrm{kDa}$ subunits.

In this study, two novel lectins, together with possible endogenous ligand glycoproteins, were found in legume trees by a unique screening method and purified. They were found only in legume trees, and the dependence of the aggregation-dissociation transition on the concentrations of specific sugars including glucose indicates that self-aggregatable lectins can link increased photosynthetic product to the release of glycoproteins to supply nitrogen, suggesting that these lectins are involved in the annual growth of legume bark.

\section{Materials and Methods}

\section{Materials}

Barks of four kinds of leguminous woody plants, Sophora japonica, Robinia pseudoacacia, Wisteria floribunda, and Cytisus scoparius, and stems of four kinds of leguminous plants, Sophora flavescens, Pisum sativum, Vicia faba, and Astragalus sinicus were collected in spring at local areas in Japan and stored at $-20^{\circ} \mathrm{C}$ until use. Affinity adsorbents, lactamyl, di $N$-acetylchitobiamyl, and maltamyl-Sepharose 4B, were prepared as described previously

[12]. Man- and GalNAc-Sepharose 4B were prepared with the aid of divinylsulfone (Sigma-Aldrich Co., St Louis, MO, USA) [13]. DiN-acetylchitobiose and sugar-biotinyl polymer (BP) probes were purchased from Lectinity Inc., (Leningrad, Russia ). Biotinylated Con A and lentil lectin (LCA) were purchased from Seikagaku Kogyo 
(Tokyo, Japan), and Sophoragrin, B-SJA-I and Robiniagrin were biotinylated with $N$-hydroxysuccinimide biotin

(Pierce, Rockford, IL, USA) in the presence of specific sugars (0.1 M Me $\alpha$-Man and Me $\beta$-GlcNAc for Sophoragrin and Robiniagrin, or Me $\beta$-Gal for B-SJA-I). Streptavidin-biotinylated peroxidase complex was purchased from Amersham (Buckinghamshire, UK). Avidin-alkaline phosphatase complex and p-nitrophenylphosphate were purchased from Sigma-Aldrich Co.

Screening of self-aggregatable lectins by solubility-insolubility transition

All the procedures were performed at $4^{\circ} \mathrm{C}$ unless otherwise stated. Bark of trees or stems (1.5 g each) of leguminous plants were homogenized using a mortar and pestle in $10 \mathrm{ml}$ of saline, or saline containing $0.5 \mathrm{M}$ maltose or $0.5 \mathrm{M}$ lactose, and extracted for $60 \mathrm{~min}$ with shaking. The extracts were centrifuged at 15,000 rpm for $60 \mathrm{~min}$, and the supernatants were extensively dialyzed against saline to remove sugars and again centrifuged. The resultant supernatants and precipitates were separately dissolved or suspended in saline at the protein concentration of $0.1 \mathrm{mg} / \mathrm{ml}$ and measured for hemagglutinating activities using trypsin-treated human type A erythrocytes [6] or for binding activities with sugar-BP probes. Under the condition, a small part of the self-aggregatable lectin in the precipitate becomes soluble, which is in equilibrium with insoluble complexes even in the absence of sugar and hemagglutinating activity was detectable. Serial dilutions of sample solutions starting at $5 \mu \mathrm{g}$ protein $/ 150 \mu \mathrm{l}$ were assayed for binding with various sugar BP-probes in TBS (1 $\mu \mathrm{g} / 100 \mu \mathrm{l})$ by 
dot-blotting for crude fractions according to methods previously described [14]. For the samples of W. floribunda bark, to avoid the interference of endogenous peroxidase, the binding assays were performed in a microtiter plate using avidin-alkaline phosphatase complex and p-nitrophenylphosphate instead of avidin-peroxidase for detection according to methods described [15].

Purification of Robinia lectins by two-step affinity chromatography

All procedures were performed at $4^{\circ} \mathrm{C}$ otherwise stated. Bark of R. pseudoacacia $(20 \mathrm{~g})$ was homogenized in $120 \mathrm{ml}$ of TBS containing $10 \mathrm{mM} \mathrm{Ca}^{2+}$ and $100 \mathrm{mM}$ GlcNAc (buffer A), extracted overnight, and centrifuged at 15,000 rpm for $45 \mathrm{~min}$. The supernatant was applied to a lactamyl Sepharose $4 \mathrm{~B}$ column $(0.7 \times 12 \mathrm{~cm})$ or a GalNAc-Sepharose column $(1.5 \times 6.5 \mathrm{~cm})$ equilibrated with buffer A and washed, and the galactose-specific lectin (B-RPL-I) bound to the column was eluted from the lactamyl column with $0.2 \mathrm{M}$ lactose or the GalNAc-Sepharose column with $0.2 \mathrm{M} \mathrm{Na}_{2} \mathrm{~B}_{4} \mathrm{O}_{7}$. The protein elution was monitored at $280 \mathrm{~nm}$. The unbound flow-through fractions were pooled and mixed with $5 \mathrm{~g}$ of diN-acetylchitobiamyl (GlcNAc )-Sepharose 4B, Man-Sepharose 6B, or maltamyl-Sepharose 6B, and dialyzed against several changes of TBS. Then the dialysate including the carrier was transferred to a column $(0.7 \times 3.0 \mathrm{~cm})$, and the column was washed with TBS. The bound protein was eluted with 0.2 M GlcNAc from a GlcNAc 2 -Sepharose 4B column, 0.2 M mannose from a Man-Sepharose 6B column, or 0.2 M maltose from a maltamyl-Sepharose 6B column. The peak fractions were 
pooled and dialyzed against water, then lyophilized.

Turbidity measurement and sugar-binding specificity

Robiniagrin solution $\left(1 \mathrm{mg} / \mathrm{ml}\right.$ ) was dialyzed against $0.2 \mathrm{M}$ EDTA and then against TBS. To $1 \mathrm{ml}$ of $\mathrm{Ca}^{2+}$-free

Robiniagrin solution in the test tube, $0.5 \mu \mathrm{l}$ aliquots of $1.0 \mathrm{M} \mathrm{CaCl}_{2}$ were repeatedly added and mixed in to gradually increase the $\mathrm{Ca}^{2+}$ concentration, and absorbance at $635 \mathrm{~nm}$ was measured at each step after $20 \mathrm{~min}$ incubation. After the turbidity reached a maximum at $1 \mathrm{mM} \mathrm{Ca}^{2+}$, 0.5-1 $\mu \mathrm{l}$ aliquots of $0.5 \mathrm{M}$ EDTA, $0.3 \mathrm{M}$ GlcNAc, or Man in TBS were repeatedly added, and $\mathrm{A}_{635}$ was measured at each step after 20 min incubation. Binding studies of purified Robinia lectins with various sugar BP-probes in TBS $(1 \mu \mathrm{g} / 100 \mu \mathrm{l})$ were performed by ELISA according to the method previously described [16].

SDS-PAGE and binding studies of Robinia lectins with biotin-lectin on the membrane

SDS-PAGE and lectin reactivity was examined for the purified Robinia lectins as previously described [14,

17]. A mixture of purified Robiniagrin and B-RPL-I (totally $5 \mu \mathrm{g}$ ) were electroblotted on to PVDF membrane after SDS-PAGE using 15\% polyacrylamide gel and cut by lane. Proteins were stained with Coomassie brilliant blue (CBB) or allowed to react with biotin-lectins $(10 \mu \mathrm{g} / \mathrm{ml})$ in TBS containing $1 \mathrm{mM} \mathrm{Ca}^{2+}$ and the color was developed with 4-chloro-1-naphthol or 3,3'-diaminobenzidine and $\mathrm{H}_{2} \mathrm{O}_{2}$ 


\section{Chemical analyses}

Protein concentration was measured by BCA Protein Assay (Pierce, Rockford, IL, USA). Protein sequencing was conducted on an Applied Biosystems model 476A protein sequencer (Foster City, CA, USA), following the instructions recommended by the manufacturer. SDS-PAGE was carried out under a reducing condition using 15\% acrylamide separation gels [16]. Carbohydrate composition of purified lectins was analysed by procedures reported previously [17]. Purified lectins were acid-hydrolysed, $N$-acetylated, and subjected to 2-aminopyridylation of the reducing sugars. The fluorescent sugars were separated by anion-exchange HPLC.

\section{Results}

Screening of self-aggregatable lectins

Self-aggregatable lectins were sought utilizing the insolubility transition of the lectin after removal of sugars by dialysis, with the extract of S. japonica bark as a positive control. Self-aggregatable lectins were found in the bark of two of three leguminous trees but not in stems of leguminous plants. As shown in Table 1, hemagglutinating activities were observed for the precipitate fractions in the dialyzed extracts of R. pseudoacacia and W. floribunda, as well as S. japonica, suggesting that self-aggregatable lectins are present in all three extracts. Precipitate fractions in other extracts did not exhibit hemagglutination, although they might contain undialyzable endogenous 
inhibitors for the lectins. Therefore, the possibility of the presence of a lectin in those fractions was also examined by a binding assay with various sugar-BP probes by dot-blotting.

The precipitate fraction of R. pseudoacacia bound to $\alpha$-Man- and $\beta$-GlcNAc-BP, suggesting the presence of a GlcNAc/Man-specific lectin with a tendency to precipitate in the absence of sugars, while the supernatant fraction bound to $\beta$-Gal- and $\alpha$-GalNAc-BP probes, which coincides with the known specificity of $R$. pseudoacacia bark lectins [18-20]. In the extract of $W$. floribunda bark, the activity of endogenous peroxidase was high and interfered with the binding assays with sugar-BP probes, the sugar-binding specificities of the fractions were demonstrated using avidin-alkaline phosphatase for detection by color development . The precipitate fraction of $W$. floribunda bound significantly to $\beta$-GlcNAc ${ }_{2}$ - and very weakly to $\alpha$-Man-BP, suggesting the presence of a GlcNAc-specific self-aggregatable lectin, while the supernatant fraction bound to $\beta$-GalNAc- and $\beta$-Gal-BP probes but not $\alpha$-Gal and $\alpha$-GalNAc-BP, suggesting the presence of two lectins in W. floribunda bark. Addition of maltose or lactose to the extraction buffer slightly enhanced the BP-sugar probe binding of the precipitate fraction in some cases, but the total binding specificities of the extracts were not changed.

Purification of Robinia lectins using combined affinity chromatography

According to the predicted sugar-binding specificities in Table 1, seven kinds of carbohydrate-immobilized adsorbents were prepared to purify R. pseudoacacia lectin by two-step affinity chromatography. As summarized 
in Figure 1(A), the GalNAc/Gal-specific lectin (B-RPL-I) in R. pseudoacacia bark was removed by binding and elution from lactamyl-Sepharose (Fig. 1 (A-a)) or GalNAc-Sepharose (Fig. 1 (A-d)) as the first step. B-RPL-I gave a single protein band of $29 \mathrm{kDa}$ from lactamyl-Sepharose (Fig. 1 (B-a)), as reported for the GalNAc-specific lectin of R. pseudoacacia [18]. On the other hand, B-RPL-I was not eluted from GalNAc-Sepharose by lactose or $0.2 \mathrm{M}$ GalNAc but was with $0.2 \mathrm{M} \mathrm{Na}_{2} \mathrm{~B}_{4} \mathrm{O}_{7}$ in a mixed form with Robiniagrin (Fig. 1 (B-d)).

As the second step, affinity chromatography was applied to the flow-through fraction to isolate the Man/GlcNAc-specific lectin (Robiniagrin) using three kinds of adsorbents. Robiniagrin bound to GlcNAc 2 -Sepharose (Fig.1 (A-b)) and Man-Sepharose (Fig. 1(A-c)) but not to maltamyl-Sepharose (data not shown). As shown in Figure 1(B-e), GlcNAc ${ }_{2}$-Sepharose gave the best purification of Robiniagrin from the remaining B-RPL-I after using GalNAc-Sepharose as the first step.

The two lectins were usually coeluted in various ratios from each column, as detected by SDS-PAGE (Fig. 1(B)), and repeated chromatography gradually reduced the contaminating lectin, suggesting that the two lectins interact. Addition of GlcNAc or Me $\alpha$-Man during the first affinity chromatography improved the separation from the coexisting lectin in all cases for Robinia, indicating that the Gal/GalNAc-specific lectin is a potential endogenous receptor for the self-aggregatable lectin.

Purification of Wisteria lectins were tried using various adsorbents developed in this study, but failed because a lactamyl-binding lectin consisting of around $30 \mathrm{kDa}$ subunits was abundantly contained in the Wisteria extract and 
interfered with the purification of the other lectin even after repeated chromatography on a lactamyl-Sepharose

column. Therefore, further characterization of self-aggregatable Wisteria lectin could not be achieved.

Glycosylation of Robiniagrin and B-RPL-I and the endogenous ligands for Robiniagrin

As summarized in Table 3, both Robiniagrin and B-RPL-I were proved to be glycoproteins containing Man, GlcNAc, Fuc, and Xyl,while Gal was detected only from Robinagrin. Both lectins were recognized with biotinylated $N$-glycan specific lectins on membrane, as shown in Fig. 2(A). The reactivity with Con A (lane B) and the carbohydrate composition of the Robiniagrin and B-RPL-I indicate that they possess comlex-type $N$-glycans with Fuc/Xyl -substituted Man ${ }_{3}$ GlcNAc$_{2}$ core. Man/GlcNAc-specific lectins, Sophoragrin and LCA (lane C and D), and a Gal/GalNAc-specific lectin, B-SJA-I (lane E) bound better to Robiniagrin than to B-RPL-I. The results coincided with that Robiniagrin contains more GlcNAc and Gal than B-RPL-I, indicating the presence of exposed GlcNAc and Gal residues at the nonreducing termini of the branch extended.from the core structure of Robiniagrin, while mannose-exposed core glycan without branches is predicted for B-RPL-I. Biotinyl Robiniagrin was found to bind to both Robiniagrin and B-RPL-I (lane F) indicating that Robiniagrin interacts with the endogenous ligands including itself. The presence of endogenous ligands of Robiniagrin was shown for the crude extract of R. pseudoacacia bark, too. As shown in Fig. 2(B), B-RPL-I and Robiniagrin are two of the major soluble proteins in the bark (lane A), and biotinyl Robiniagrin bound to $31 \mathrm{kDa}$ component in addition to B-RPL-I 
and Robiniagrin (lane B). Because the most prominent proteins in the bark of $R$. pseudoacacia has been shown to be a family of lectins of 26-31 kDa [18-20], our finding suggests the possibility that the interaction among the lectins occurs in the bark.

Self-aggregation and carbohydrate-binding specificity of Robiniagrin

As shown by the turbidity in Figure 3(A), the Robiniagrin solution was precipitated by increasing the $\mathrm{Ca}^{2+}$ concentration, and the turbidity reached a plateau at more than $1 \mathrm{mM} \mathrm{Ca}^{2+}$. The precipitate of Robiniagrin was dissociated by the addition of EDTA, $1 \mathrm{mM}$ GlcNAc, or, to a lesser extent, $5 \mathrm{mM}$ Man. Robiniagrin was demonstrated to undergo self-aggregation depending on sugar and $\mathrm{Ca}^{2+}$ concentrations. As shown in Fig. 3(B), Robiniagrin bound concentration-dependently with $\beta$-Glc- $\alpha$-Man- $\alpha$-Gal- $\beta$-GalNAc-, $\beta$-GlcNAc 2 - and $\beta$-GlcNAc-BP probes, but not with other sugar probes. Compairing the results with the efficient binding of Robiniagrin to GlcNAc ${ }_{2}$ - and Man-Sepharose but not to maltamyl-Sepharose (Fig. 1(A)), Robiniagrin exhibits affinity toward $\beta$-GlcNAc and $\alpha$-Man but not to $\alpha$-Glc, which coincides with the inhibitory activities of the sugars toward self-aggregation of Robiniagrin. Although Robiniagrin exhibited the highest binding to $\beta$-Glc-BP probe, Robiniagrin could not be purified by using a cellobiamyl Sepharose column by unknown reason (data not shown), and the purification procedure in this study is the efficient one.

In contrast, B-RPL-I bound concentration-dependently with an $\alpha$-GalNAc, LacNAc, Lac and $\beta$-GalNAc probe, 
but not with other sugar probes (Fig. 3(C)). The B-RPL-I solution remained soluble under these conditions and its turbidity did not change in the presence of $\mathrm{Ca}^{2+}$, irrespective of sugar concentration (data not shown). Minimum carbohydrate concentrations required for hemagglutination-inhibition indicate that B-RPL-I exhibits a prominent affinity to GalNAc (0.058 $\mathrm{mM})$ and, to a lesser extent, to Lac $(0.68 \mathrm{mM})$ and $\mathrm{Gal}(2.3 \mathrm{mM})$. The carbohydrate-binding activities of the purified lectins were congruent with the specificities predicted from the screening of R. pseudoacacia extract, suggesting that the purified lectins are major lectin constituents in Robinia bark.

$N$-terminal sequences of Robiniagrin and B-RPL-I

As summarized in Table 3, the N-terminal 8 amino acid sequence of Robiniagrin was found to be identical to that of RPbAII (cDNA LECRPA3) [19], while the 18 amino acid sequence of B-RPL-I was identical to that of a previously reported GalNAc-specific lectin, RBL [20] or RpbAI (cDNAs LECRPA1 or LECRPA2) [19]. The relatively low molecular weight of Robiniagrin on SDS-PAGE (27 kDa) compared to B-RPL-I (29 kDa, Fig. 1) was consistent with that of RPbAII [19].

\section{Discussion}


Novel self-aggregatable lectins, Robiniagrin and Wisteriagrin

We designed a unique method to screen for self-aggregatable lectins based on the solubility-insolubility

transition property of these lectins. The finding of two self-aggregatable lectins out of seven samples

demonstrated the effectiveness of the screening method. Although the bark lectins of $R$. pseudoacacia have been

studied extensively since 1978 [19-21], the unique self-aggregatable character of one lectin has been overlooked.

Fetuin-agarose affinity chromatography followed by ion-exchange FPLC separated lectins from the Robinia bark into RPbAI and RPbAII [18]; RPbAI is a major lectin consisting of five Gal/GalNAc-specific isolectins, while the carbohydrate-specificity of RPbAII has been unknown [19]. The screening method in this study and purification with GlcNAc 2 -Sepharose revealed RPbAII to be a self-aggregatable lectin of distinct specificity from other lectins in the Robinia bark and seed.

Distribution and common characteristics of self-aggregatable lectins

Adding the novel Robinia lectin, the characteristic properties of the self-aggregatable lectins found to date are summarized in Table 3. Self-aggregatable lectins are: 1) found in only the bark of overwintering legume trees, 2) Man-, GlcNAc- or Glc-specific, and 3) coexistent with GalNAc/Gal-specific lectins. Although a GalNAc/Gal-specific lectin has not been found in C. lutea, the second major bark protein after CLA I is a lectin-related glycoprotein (CLLRP) that has a higher homology to B-RPL-I in this study than to CLA I and II [11]. 
The fact that CLLRP is devoid of carbohydrate-binding activity because of the insertion of three residues into the binding site may suggest the functional unimportance of GalNAc/Gal-binding activity compared to the Man-,

GlcNAc-, or Glc-binding activity of self-aggregatable lectins.

Function achieved by interaction of self-aggregatable lectin with endogenous ligands

This study supports the hypothesis presented in our previous study that bark lectins may play a specific role in legume trees through sugar-specific interaction with the endogenous ligands [10]. Recently we found that Sophoragrin sugar-specifically forms complexes of various sizes with B-SJA-I, proving that B-SJA-I is an endogenous ligand for Sophoragrin because they are simultaneously present in the vacuole [10]. Compared with that seed storage proteins of legume annual plant, Lupinus conglutins, electrostatically aggregate depending on the $\mathrm{Ca}^{2+} / \mathrm{Mg}^{2+}$ concentration and are dissociated by charged compounds, but not by neutral sugars [22], self-aggregatable lectins and coexisting GalNAc/Gal-specific lectins or CLLRP in bark are assumed to cooperate in vivo to achieve an integrated function depending on sugar signalling. For example, self-aggregatable lectins can dissociate glycoproteins in response to increased photosynthesis to supply nitrogen for the perennial growth of legume barks. Robiniagrin and Sophoragrin have been shown to possess lower sequence homology with Gal/GalNAc-specific lectins in barks, and most legume lectins found in seeds[1, 7, 11], indicating that self-aggregatable lectins would have differentiated long ago to perform a specialized function. We therefore 
propose that the self-aggregatable lectins constitute a new group of functional lectins.

\section{Acknowledgements}

We thank Dr. F. Shimozono (Koishikawa Arboretum, Graduate School of Tokyo University) for his help in

collecting materials, Dr. K. Tazaki and Dr. K. Yoshida for helpful suggestions on B-RPL-1, and Katherine Ono for editing the English. This work was supported in part by Research Grant-in-Aid for Scientific Research (C) No.

12680607 (HO) from Ministry of Education, Culture, Sports, Science and Technology of Japan.

\section{References}

[1] N. Sharon and H. Lis, Legume lectins--a large family of homologous proteins., FASEB J. 4 (1990)

3198-3208.

[2] M.E. Etzler. in (Allen, H.J. and Kisailus, E.C., eds.) Glycoconjugates, Marcel Dekker, Inc., New York 1992,

pp. 521-539.

[3] E.J.M. Van Damme, W.J. Peumans, A. Pusztai and S. Bardocz, Handbook of plant lectins: properties and biomedical applications, Jhon Wiley \& Sons, Chichester, 1998.

[4] H. Rudiger, Plant lectins - more than just tools for glycoscientists: occurrence, structure, and possible functions of plant lectins., Acta Anat. 161 (1998) 130-152. 
[5] A.M. Hirsch, Role of lectins (and rhizobial exopolysaccharides) in legume nodulation., Curr. Opin. Plant

Biol. 2 (1999) 320-326.

[6] M. Ueno, H. Ogawa, I. Matsumoto and N. Seno, A novel mannose-specific and sugar specifically aggregatable lectin from the bark of the Japanese pagoda tree (Sophora japonica), J. Biol. Chem. 266 (1991) 3146-3153.

[7] E.J.M. Van Damme, A. Barre, P. Rouge and W. Peumans, Molecular cloning of the bark and seed lectins from the Japanese pagoda tree (Sophora japonica), Plant Mol. Biol. 33 (1997) 523-536.

[8] M. Ueno, T. Arai, K. Kojima, K.H. Ogawa, I. Matsumoto and N. Seno, Improved affinity chromatographic purification of D-mannose-N-acetyl-D-glucosamine specific lectin from the bark of Sophora japonica eliminating the loss by sugar specific self-aggregation, J. Chromatogr. 597 (1992) 197-200.

[9] K. Baba, M. Ogawa, A. Nagano, H. Kuroda and K. Sumiya, Developmental changes in the bark lectin of Sophora japonica L., Planta 183 (1991) 462-470.

[10] H. Ueda, H. Fukushima, Y. Hatanaka and H. Ogawa, Solubility-insolubility interconversion of sophoragrin, a mannose/glucose-specific lectin in Sophora japonica (Japanese pagoda tree) bark, regulated by the sugar-specific interaction, Biochem J 382(Pt 3), (2004) 821-829.

[11] E.J. Van Damme, A. Barre, V. Bemer, P. Rouge, F. Van Leuven and W.J. Peumans, A lectin and a lectin-related protein are the two most prominent proteins in the bark of yellow wood (Cladrastis lutea). 
Plant Mol. Biol. 29 (1995) 579-598.

[12] I. Matsumoto, H. Kitagaki, Y. Akai, Y. Ito and N. Seno, Derivatization of Epoxy-Activated Agrose with Various Carbohydrates for the Preparation of Stable and High-Capacity Affinity Adsorbents : Their Use for Affinity Chromatography of Carbohydrate-Binding Proteins., Anal. Biochem. 116 (1981) 103-110.

[13] N. Fornstedt and J. Porath, Characterization studies on a new lectin found in seeds of Vicia ervilia, FEBS Lett 57 (1975) 187-191.

[14] H. Matsumoto, A. Natsume, H. Ueda, T. Saitoh and H. Ogawa, Screening of a unique lectin from 16 cultivable mushrooms with hybrid glycoprotein and neoproteoglycan probes and purification of a novel N-acetylglucosamine-specific lectin from Oudemansiella platyphylla fruiting body, Biochim Biophys Acta 1526 (2001) 37-43.

[15] E. Harlow and D. Lane. Antibodies, Cold Spring Harbor Laboratory, New York 1988, p. 597.

[16] H. Ueda, K. Kojima, T. Saitoh and H. Ogawa, Interaction of a lectin from Psathyrella velutina mushroom with N-acetylneuraminic acid, FEBS Lett 448 (1999) 75-80.

[17] H. Uchibori-Iwaki, A. Yoneda, S. Oda-Tamai, S. Kato, N. Akamatsu, M. Otsuka, K. Murase, K. Kojima, R. Suzuki, Y. Maeya, and H. Ogawa, The changes in glycosylation after partial hepatectomy enhance collagen binding of vitronectin in plasma, Glycobiology 10 (2000) 865-874.

[18] K. Tazaki, and Yoshida, K., The bark lectins of Robinia pseudoacacia: purification and partial 
characterization., Plant Cell Physiol. 33 (1992) 125-129.

[19] E.J. Van Damme, A. Barre, K. Smeets, S. Torrekens, F. Van Leuven, P. Rouge and W.J. Peumans, The bark of Robinia pseudoacacia contains a complex mixture of lectins.Characterization of the proteins and the cDNA clones., Plant Physiol. 107 (1995) 833-843.

[20] V. Horejsi, Haskovec, C., and Kocourek, J., Studies on lectins. XXXVIII. Isolation and characterization of the lectin from black locust bark (Robinia pseudacacia L.). Biochim. Biophys. Acta 532 (1978) 98-104.

[21] K. Yoshida, Baba, K., Yamamoto, N., and Tazaki, K., Cloning of a lectin cDNA and seasonal changes in levels of the lectin and its mRNA in the inner bark of Robinia pseudoacacia., Plant Mol. Biol. 25 (1994) 845-853.

[22] R.B.Ferreira, R.L.Freitas, A.R. Teixeira, Self-aggregation of legume seed storage proteins inside the protein storage vacuoles is electrostatic in nature, rather than lectin-mediated, FEBS Lett 534 (2003) 106-110 


\section{Legends to Figures}

Figure 1 Purification of Robinia lectins by two-step affinity chromatography on various sugar adsorbents

(A) and SDS-PAGE of Robinia lectins eluted from each affinity column (B).

(A) The extract of $R$. pseudoacacia bark was applied to first-step affinity chromatography on a

lactamyl-Sepharose column $(0.7 \times 12 \mathrm{~cm})$ (a) or a GalNAc-Sepharose column $(1.5 \times 6.5 \mathrm{~cm})(\mathrm{d})$. The bound

protein (B-RPL-I) was eluted with $0.2 \mathrm{M}$ lactose in TBS or $0.2 \mathrm{M} \mathrm{Na}_{2} \mathrm{~B}_{4} \mathrm{O}_{7}(\mathrm{pH}$ 8.0), respectively. For the second affinity chromatography, the pass-through fractions from a lactamyl-Sepharose column were pooled and mixed

with $5 \mathrm{~g}$ of $\mathrm{GlCNAc}_{2}$ (b), Man-Sepharose 6B (c), or maltamyl-Sepharose 6B, dialyzed against several changes of TBS, and then the dialysate was packed into the column. Each column $(0.7 \times 3.0 \mathrm{~cm})$ was washed with TBS, and the bound protein was eluted with 0.2 M GlcNAc, 0.2 M mannose, or 0.2 M maltose, respectively. No protein was eluted from the maltamyl-Sepharose column. The pass-through fractions from the GalNAc-Sepharose column

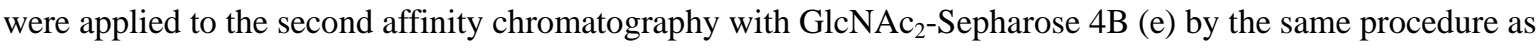
described above. (B) Five $\mu$ g of lectins were loaded on each lane of 15.0\% acrylamide gel, run for SDS-PAGE in the presence of 2-mercaptoethanol, and stained with silver.

Figure 2 Lectin reativities of robiniagrin and B-RPL-I. (A) and bark extract of $R$. pseudoacacia (B)

(A) A mixture of Robiniagrin and B-RPL-I (totally $5 \mu$ gper lane) was electrophoresed on a 
15.0 \% polyacrylamide gel and electroblotted onto a PVDF membrane. The blotted membrane was cut by lane and proteins were stained with CBB (lane a) or allowed to react with biotin-lectins (10 $\mu \mathrm{g} / \mathrm{ml}$, lane b-f) in TBS (pH 7.5). The color was developed with $\mathrm{H}_{2} \mathrm{O}_{2}$ and 4-chrolo-1-napht hol or DAB as described in the text. Each lane was stained with biotin-Con A (lane b), biotin Sophoragrin (lane c), biotin-LCA (lane D), biotin-B-SJA-I (lane e), and biotin-Robiniagrin (lane f). (B) Crude bark extract (5 $\mu \mathrm{g}$ as protein per lane) was electrophoresed on a $12.5 \%$ polyacrylamide gel and western blotting was performed as described above and proteins were stained with CBB (lane 1) and biotin-Robiniagrin (lane 2).

Figure 3 Solubility-insolubility transition of purified Robiniagrin (A), and reactivities with BP-sugar

probes of Robiniagrin (B) and B-RPL-I (C).

(A) The $\mathrm{Ca}^{2+}$ concentration of the Robiniagrin solution $(1 \mathrm{mg} / \mathrm{ml})$ in TBS was increased gradually by adding 0.5 $\mu \mathrm{l}$ aliquots of $1 \mathrm{M} \mathrm{Ca}^{2+}$ solution. After the turbidity reached a maximum at $1 \mathrm{mM} \mathrm{Ca}^{2+}$, concentrated EDTA or GlcNAc solution was added to the final concentration indicated. After 20 min incubation for each step, the absorbance of the mixture solution was measured at $635 \mathrm{~nm}$ with a spectrophotometer, as described in the text. The absorbance of each solution was corrected by subtracting that of Robiniagrin in $\mathrm{Ca}^{2+}$-free TBS as a control, and the turbidity (\%) is represented by the percentage of the corrected absorbance of the solution to that in the 
presence of $1 \mathrm{mM} \mathrm{Ca}^{2+}$. (B) and (C) The solution of Robinia lectins was serially diluted in TBS (pH 7.5) and immobilized on microtiter plates. Immobilized lectins were allowed to react with various BP-sugar probes (10 $\mu \mathrm{g} / \mathrm{ml}$ ), and the bound BP-sugar probes were detected as described in the text. Symbols used for BP-sugar probes: $\beta-\operatorname{Glc}(\diamond), \alpha-\operatorname{Man}(\bigcirc), \alpha-\operatorname{Gal}(\diamond), \alpha-\operatorname{GalNAc}(\square), \beta-\operatorname{GalNAc}(\times), \operatorname{LacNAc}(\boldsymbol{\Delta}), \operatorname{Lac}(\triangle), \operatorname{GlcNAc} 2 \quad \bigcirc)$ $\beta$-GlcNAc (*). (B) Concentration-dependency of the binding of Robiniagrin to BP-sugar probes. Lac-, LacNAc-, $\alpha$-GalNAc, and $\alpha$-Glc-BP bound very little with Robiniagrin. (C) Concentration-dependency of the binding of B-RPL-I to BP-sugar probes. $\beta$-Glc-, $\beta$-GlcNAc-, $\alpha$-Glc-, GlcNAc2- and $\alpha$-Gal-BP bound very little as $\alpha$-Man with B-RPL-I 
Fig. 1
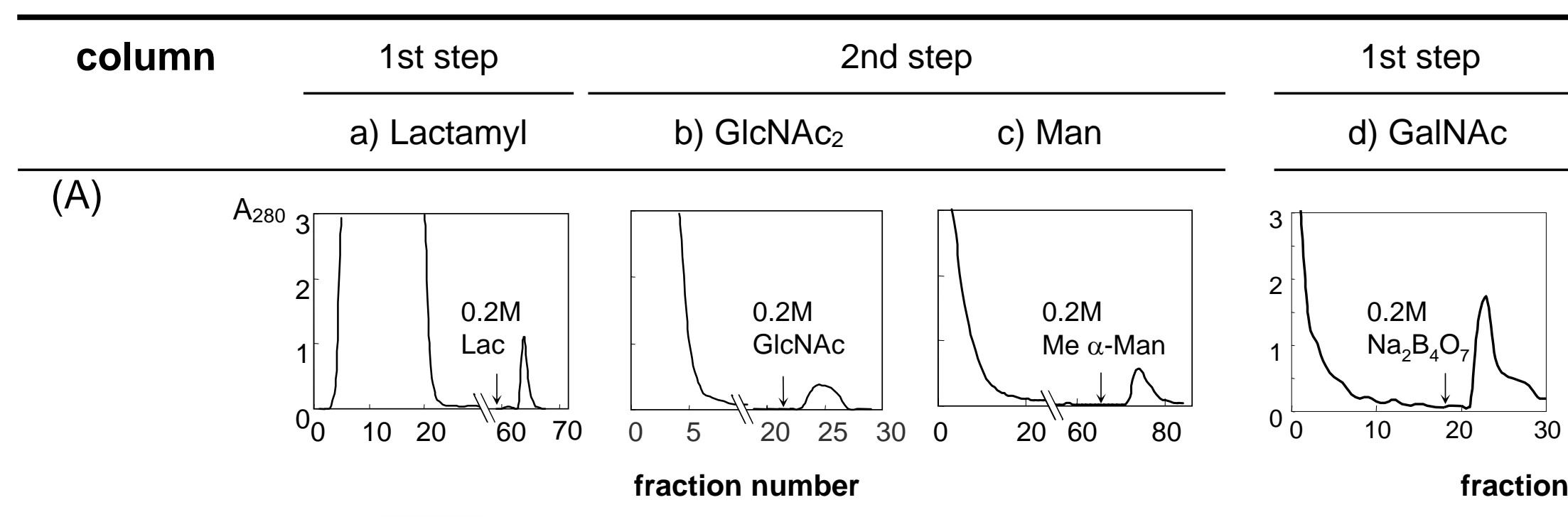

$\frac{\text { 2nd step }}{\text { e) } \mathrm{GlcNAc}_{2}}$

(B)

B-RPL-I 29kD

Robiniagrin 27kD 
Figure 2

(A)

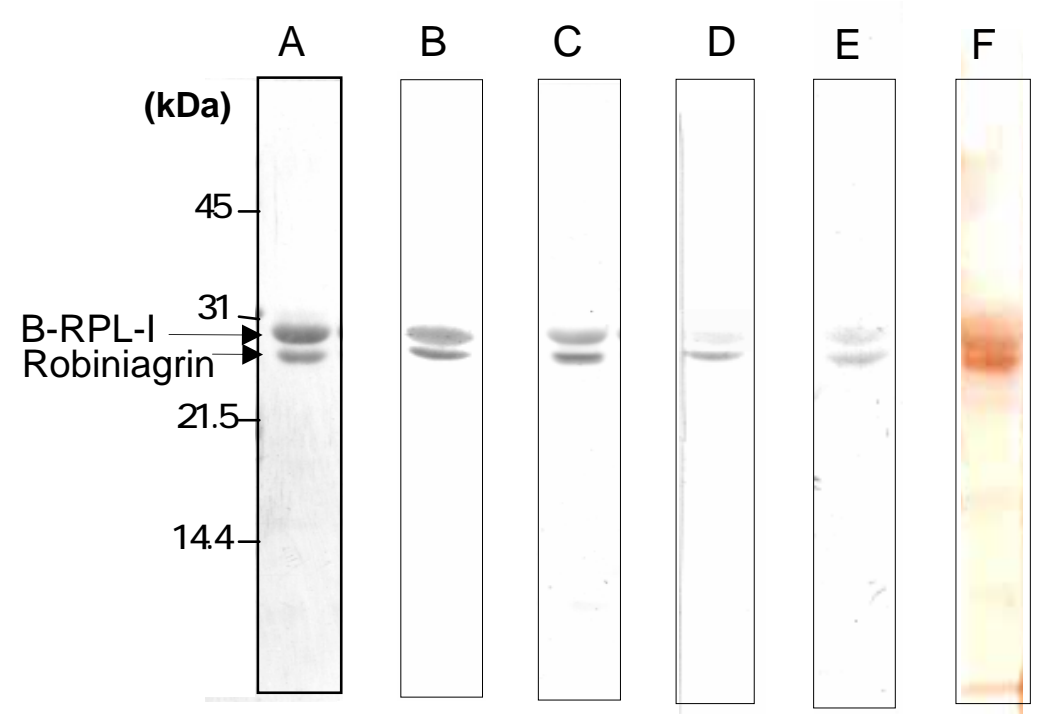

(B)

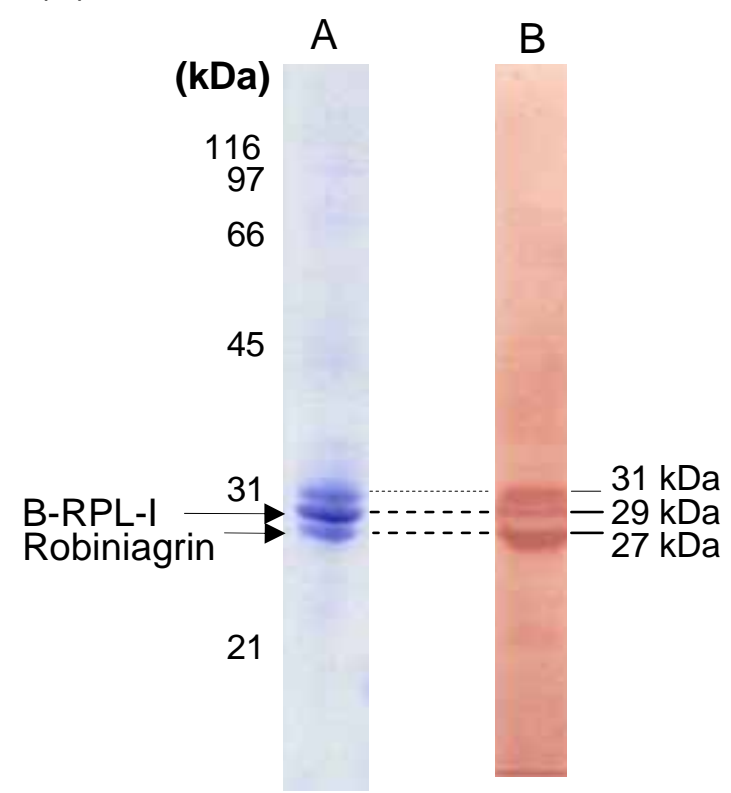


Fig. 3

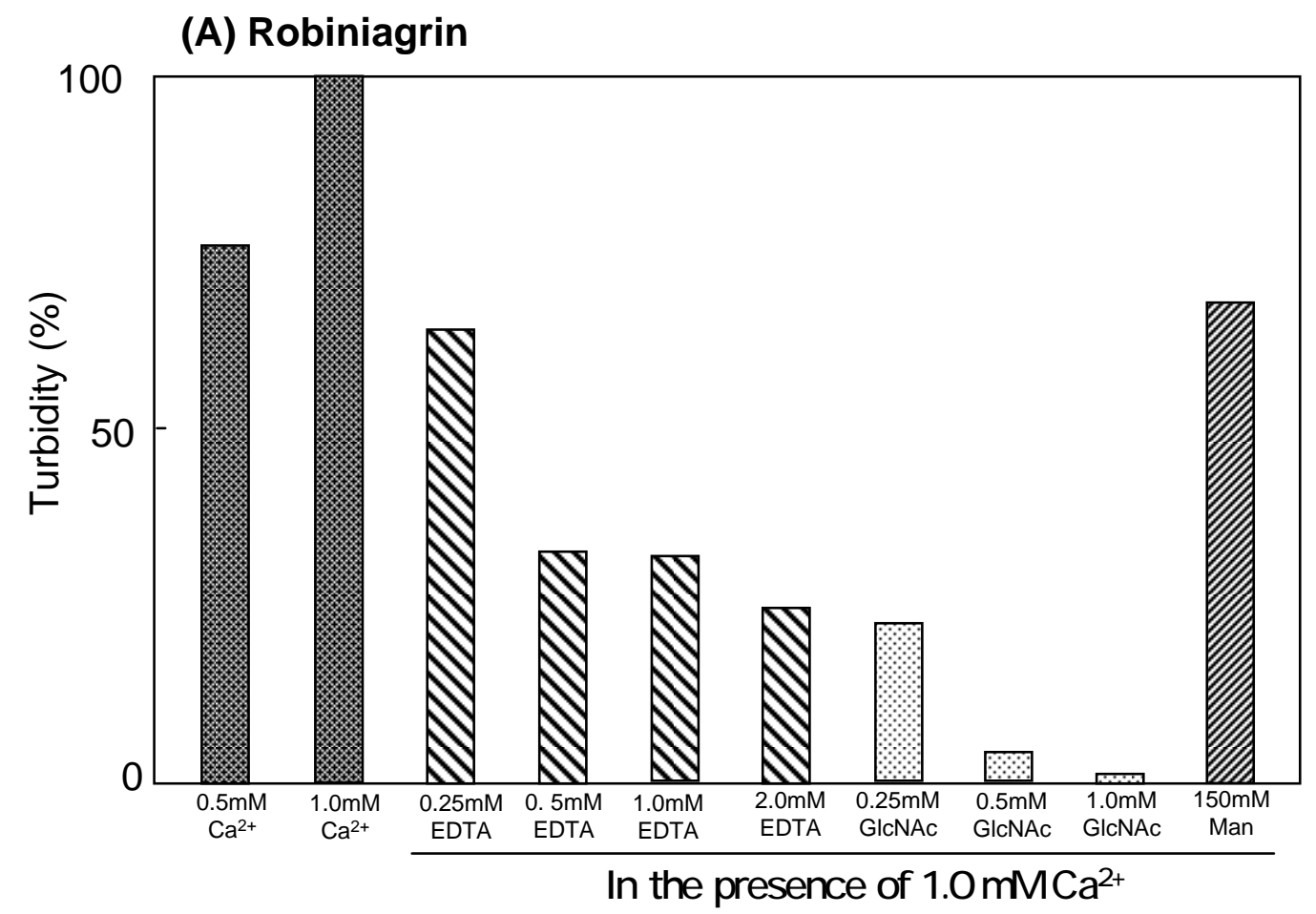

(B) Robiniagrin

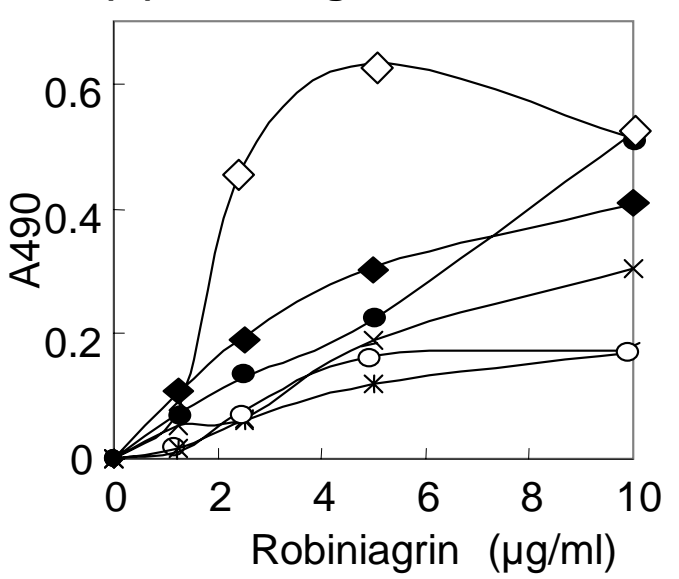

(C) B-RPL-1

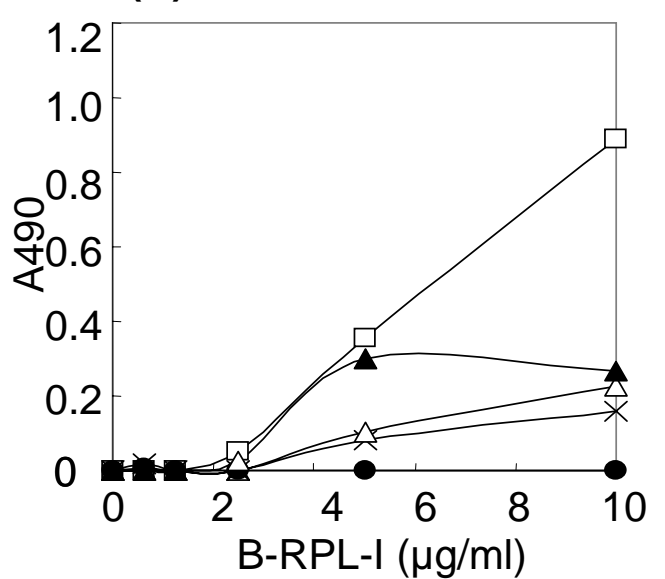


Table 1 Screening of self-aggregatable lectins among leguminous woods and plants. Hemagglutination activities and binding with sugar-BP probe were measured by dot blotting after dialysis of the extracts as described in the text.

\section{Source of} bark or stem

Precipitate fraction

$\begin{array}{ll}\text { Hemagglutinating } & \text { Bound sugar-BP } \\ \text { activity } & \text { probe }\end{array}$

Supernatant fraction

$\begin{array}{ll}\text { Hemagglutinating } & \begin{array}{l}\text { Bound sugar-BP } \\ \text { probe }\end{array} \\ \text { activity } & \text {. }\end{array}$

\section{Legume trees}

Sophora japonica

$+$

$\alpha$-Glc, $\alpha$-Man

$+$

$\beta$-Gal

Robinia pseudoacacia

$+$

$\alpha$-Man, $\beta$-GIcNAc

$+$

$\beta$ - Gal, $\alpha$-GalNAc

Wisteria floribunda *

$+$

$\beta-\mathrm{GlcNAc}_{2}$

$+$

$\beta$-GalNAc, Lac

Cytisus scoparius

- $\quad \beta$-Gal, $\alpha$-Man, $\beta$-GIcNAc

$+$

$\alpha-$ Man, Lac

\section{Legume plants}

Sophora flavescens

- $\quad \beta$-Gal, $\alpha$-Man, $\beta$ - GlcNAc

$+$

$\beta$-Gal, $\alpha$-Man, $\beta$-GlcNAc

Pisum sativum

$-$

$\alpha$-Glc, $\alpha$-Man

$+$

$\alpha-$ Man

Vicia faba

$-$

$\alpha$-Man, $\beta$-GIcNAc

$-$

$\beta$-Gal, $\beta$-GlcNAc

\section{Astragalus sinicus}

$-\quad$ Lac

- $\quad \beta$-GIcNAc

${ }^{*}$ Binding activity of the $W$. floribunda fractions with sugar-BP probes was determined using avidin-alkaline phosphatase and $p$-nitrophenylphosphate in a microtiterplate because endogenous peroxidase interfered with the detection of the binding assays while assays were performed using avidin-biotinperoxidase and 4-chloro-1-naphthol/ $\mathrm{H}_{2} \mathrm{O}_{2}$ for fractions from other plants. 
Table 2 Carbohydrate composition of Robiniagrin and B-RPL-1.

Values are given in molar ratio by taking that of Man as 3.

\begin{tabular}{lcccll}
\hline \multirow{2}{*}{ Lectin } & \multicolumn{5}{c}{ Carbohydrate composition } \\
\cline { 2 - 6 } & Man & GlcNAc & Fuc & Xyl & Gal \\
\hline Robiniagrin & 3.00 & 3.53 & 1.78 & 0.16 & 0.63 \\
B-RPL-1 & 3.00 & 2.12 & 1.22 & 1.04 & Not detected \\
\hline
\end{tabular}


Table $3 \mathrm{~N}$-terminal amino acid sequences of robiniagrin and B-RPL-I.

Sequences of LECRPA1, 2 and 3 were adapted from Ref. [18].

\begin{tabular}{|c|c|}
\hline Lectin & Sequence \\
\hline \multirow[t]{2}{*}{ Robiniagrin } & AEGISFNF \\
\hline & $\bullet \bullet \bullet \bullet \bullet \bullet$ \\
\hline LECRPA3 & AEGISFNFTN \\
\hline \multirow[t]{2}{*}{ B-RPL-I } & TGSLSFSFPKFMPNQP?L \\
\hline & $\bullet \cdots \cdots \cdots \cdots \cdots \bullet \bullet \bullet \bullet$ \\
\hline \multirow[t]{2}{*}{ LECRPA1 } & TGSLSFSFPKFAPNQPYLI \\
\hline & $\bullet \bullet \bullet \bullet \bullet \bullet \bullet \bullet \bullet \bullet \bullet \bullet$ \\
\hline LECRPA2 & TGSLSFSFPKFMPNEPDL \\
\hline
\end{tabular}


Table 4 Properties of self-aggregatable lectins

\begin{tabular}{|c|c|c|c|c|}
\hline $\begin{array}{l}\text { Lectin } \\
\text { [Reference] }\end{array}$ & $\begin{array}{l}\text { Robiniagrin } \\
\text { (this study) }\end{array}$ & $\begin{array}{l}\text { Sophoragrin } \\
\text { [6] }\end{array}$ & $\begin{array}{l}\text { CLA I } \\
{[11]}\end{array}$ & $\begin{array}{l}\text { CLA II } \\
{[11]}\end{array}$ \\
\hline Source & $\begin{array}{l}\text { R. pseudoacacia } \\
\text { (black locust) } \\
\text { bark }\end{array}$ & $\begin{array}{l}\text { S. japonica } \\
\text { (Japanese } \\
\text { pagoda tree) } \\
\text { bark }\end{array}$ & $\begin{array}{l}\text { C. lutea } \\
\text { (yellowwood) } \\
\text { bark }\end{array}$ & $\begin{array}{l}\text { C. lutea } \\
\text { (yellowwood) } \\
\text { bark }\end{array}$ \\
\hline $\begin{array}{l}\text { Sugar } \\
\text { specificity }\end{array}$ & $\begin{array}{l}\beta-G \mid c>\alpha-M a n \\
>\beta \text {-GIcNAc }\end{array}$ & $\begin{array}{l}\alpha-\operatorname{Man}=\beta- \\
\text { GlcNAc > Glc }\end{array}$ & Man > Glc & Man > Glc \\
\hline $\begin{array}{l}\text { Subunit } \\
\text { molecular } \\
\text { weight }\end{array}$ & 27,000 & $\begin{array}{l}19,000 \\
18,000 \\
15,000 \\
13,000\end{array}$ & $\begin{array}{l}17,000 \\
15,000\end{array}$ & 30,000 \\
\hline $\begin{array}{l}\text { Counterpart } \\
\text { lectin and its } \\
\text { sugar specificity }\end{array}$ & $\begin{array}{l}\text { B-RPL-I } \\
\alpha-\text { GalNAc }>\text { Lac } \\
\text { NAc>Gal }\end{array}$ & $\begin{array}{l}\text { B-SJA-I } \\
\text { Lac > GalNAC } \\
>\text { Gal }\end{array}$ & \multicolumn{2}{|c|}{$\begin{array}{l}\text { CLLRP, Inactivated homologue } \\
\text { of B-RPL-I in R. pseudoacasia } \\
\text { bark [9] }\end{array}$} \\
\hline
\end{tabular}

